\title{
EFFECT OF SUCTION USING MORIA MICROKERATOME ON MACULAR AND RETINAL NERVE FIBER LAYER THICKNESS DURING LASIK USING OPTICAL COHERENCE TOMOGRAPHY
}

\author{
By
El-Saied El-Mahdy El-Saied, Younis El-Saied Abd El-Hafez and Ahmed Mohamed Sobhy

Department of Ophthalmology, Faculty of Medicine, Al-Azhar University

Corresponding author: El-Saied El-Mahdy El-Saied,

Mobile: (+20) 01000407905, E-mail: merehanreda@yahoo.com

\begin{abstract}
Background: Laser in situ keratomileusis (LASIK) combines keratomileusis with the accuracy of the excimer laser and is used worldwide for correction of a broad range of refractive abnormalities.

Objective: To asses structural and functional changes of macular and NFL using spectral domain optical coherence tomography (SD-OCT) following LASIK surgery using moria microkeratome.

Patients and Methods: A total of 50 were enrolled in our study to be examined before and one month after operation using OCT device Al-Azhar University Hospital (Damietta). A complete ophthalmological examination included uncorrected visual acuity; best corrected visual acuity, full slit lamp examination and corrected tonometery. Examination was done by optical coherence tomography to record macular and NFL thickness.
\end{abstract}

Results: There was no effect on the thickness of the project before the operation $(13.66 \pm 18.99)$ and after the operation $(13.31 \pm 18.87)$. The results also showed that there was no effect on the thickness of the nerve fibers before the operation $(5.31 \pm 40.18)$ and after the operation $(5.33 \pm 39.90)$.

Conclusion: LASIK is a safe procedure on posterior segment of the eye, Suction with no effect on macular and retinal nerve fiber layers thickness.

Keywords: Moriamicrokeratome, Suction, LASIK, Optical coherence tomography, Retinal nerve fiber layer, Macular thickness.

\section{INTRODUCTION}

Laser in situ keratomileusis (LASIK) is currently the most common refractive surgery procedure. However, LASIK procedure reshapes the cornea to enable light entering the eye to be properly focused on retina for clearer vision this done by suction ring and microkeratome applied to cornea to creat a flap and beam of laser is applied to reshape the cornea, in most cases the procedure completed within 15 minutes and results can usually be seen in as little as 24 hours (Bagetta and Nucci, 2015).

Moria microkeratome is a surgical instrument with an oscillating blade designed for creating corneal flap in LASIK. The normal human cornea varies around 500 to 600 micrometers and in LASIK microkeratome creats 83 to 180 
micrometers thick flap (Eldaly et al., 2019).

Suction ring is placed on the eye to stabilize it during the process of creating the flap, during this process IOP increased up to $70 \mathrm{mmHg}$; the suction during surgery affects retinal microcirculation. Research shows that whenever the IOP rise $10 \mathrm{~mm} \mathrm{Hg}$, the surrounding blood flow of optical disc decreases $7.4 \%-8.4 \%$. Instantaneous changes of suction may cause ischemia-reperfusion injury; the suction during surgery caused mechanical stretch to the retina, sudden changes of IOP may cause mechanical stretch to vitreous base, and then cause posterior vitreous detachment, even retinal detachment (Corcoran, 2015).

It has been suggested that the transient IOP elevation during LASIK may result in short term retinal and optic nerve ischemia, which therefore may compromise the structural and functional integrity of these ocular structures (Solomon et al., 2011).

Spectral domain OCT (SD OCT) represents a prevalent imaging technique that among others enables a valid quantitative and qualitative analysis of the peripapillary RNFL. Moreover, recent SD OCT software provides a selective evaluation of the inner retinal layers at the macula represent ganglion cell complex (GCC), which includes the nerve fiber layer (NFL), the ganglion cell layer (GCL), and the inner plexiform layer (IPL), providing valuable information regarding early preperimetric glaucomatous ganglion cell damage Furthermore, latest OCT ganglion cell analysis (GCA) algorithms can demarcate the macular ganglion cell-inner plexiform layer (GC-IPL) while excluding the NFL (Zivkovic et al., 2017).

The present study aimed to asses structural and functional changes regarding macular and NFL thickness using spectral domain optical coherence tomography (SD-OCT) following LASIK surgery using moriamicrokeratome.

\section{PATIENTS AND METHODS}

A total of 50 eyes were enrolled in our study Al-Azhar University Hospital (Damietta).

\section{Inclusion criteria:}

Normal ophthalmological fundus examination and 18-40 years old of either gender.

\section{Exclusion criteria:}

Patients having optic neuropathy, retinopathy, previous intraocular surgery and previous attacks of chorioretinits.

An informed written consent was taken from every patient before history taking and investigation.

\section{All participants were subjected to:}

1. History of any illness or previous operation

2. Examination:

- Visual acuity measurement using landolt's broken ring chart.

- Manifest refraction using autorefractometer.

- Evaluation of best corrected visual acuity.

- Slit lamp biomicroscopy to examine the cornea, determination of anterior champer depth and noting abnormalities in iris or lens. 
- Pupillary examination.

- Fundus examination: dilated fundus examination to exclude any pathological changes in retina.

- Measurement of intraocular pressure.

- Optical coherence tomography (Topcon 3D 2000 OCT): before and one month after operation to define thickness of macula and retinal nerve fiber layer.

\section{OCT scanning:}

- Mydriatic eye drops was instilled into patients eyes prior to OCT examination.

- Analysis protocol was used to obtain circular maps centered around the fovea. It included also numerical values for the foveal thickness in microns and other values measuring macular thickness divided into quadrants centered around the foveal center.

- Measurement results were presented using assigned colors to indicate retinal thickness in the region under analysis:

1. Green: Thickness within normal according sex and age.

2. Yellow: Moderate thinning.

3. Red: Severe thinning.
4. Orange: Moderate thickening.

5. Purple: Severe thickening (Gabriele et al., 2011).

- The macular retinal map, divides the region into a central disc with a radius of 500 microns, and two concentric rings divided into four quadrants. The analysis program reports the corresponding mean thickness in each of the areas. The scan of a normal retina in the macular region appears green (200 to 250 microns) (Gabriele et al., 2011).

\section{Statistical analysis:}

Recorded data were analyzed using the statistical package for social sciences, version 20.0 (SPSS Inc., Chicago, Illinois, USA). Quantitative data were expressed as mean \pm standard deviation (SD). Qualitative data were expressed as frequency and percentage. Independentsamples t-test of significance was used when comparing between two means. Chisquare (x2) test of significance was used in order to compare proportions between two qualitative parameters. The confidence interval was set to $95 \%$ and the margin of error accepted was set to $5 \%$. The p-value was considered significant when $\mathrm{P}$-value $<0.05$.

\section{RESULTS}

This was a prospective study that included 50 eyes, 16 eyes of male patients \& 34 eyes of female patients with age ranged (18-40 years).Both eyes of all patients were investigated and enter the study. The number of eyes with best corrected visual acuity post-operative $6 / 12$ was two, 6/9 was nine, $6 / 6$ was thirty nine (Table 1). 
Table (1): Distribution of the studied cases according to demographic data, UCVA, postoperative BCVA and intraocular pressure $(n=50)$

\begin{tabular}{|c|c|c|}
\hline & No. & $\%$ \\
\hline \multicolumn{3}{|l|}{ Sex } \\
\hline Male & 16 & 32.0 \\
\hline Female & 34 & 68.0 \\
\hline \multicolumn{3}{|l|}{ Age (years) } \\
\hline Min. - Max. & \multicolumn{2}{|c|}{$19.0-40.0$} \\
\hline Mean \pm SD. & \multicolumn{2}{|c|}{$28.64 \pm 5.72$} \\
\hline Median (IQR) & \multicolumn{2}{|c|}{$28.0(26.0-32.0)$} \\
\hline $\begin{array}{l}\text { UCVA } \\
6 / 12\end{array}$ & 2 & 4.0 \\
\hline $6 / 18$ & 9 & 18.0 \\
\hline $6 / 24$ & 11 & 22.0 \\
\hline $6 / 36$ & 10 & 20.0 \\
\hline $6 / 60$ & 18 & 36.0 \\
\hline Min. - Max. & \multicolumn{2}{|c|}{$0.32-0.79$} \\
\hline Mean \pm SD. & \multicolumn{2}{|c|}{$0.64 \pm 0.14$} \\
\hline Median (IQR) & \multicolumn{2}{|c|}{$0.68(0.56-0.79)$} \\
\hline $\begin{array}{l}\text { BCVA } \\
6 / 12\end{array}$ & 2 & 4.0 \\
\hline $6 / 9$ & 9 & 18.0 \\
\hline $6 / 6$ & 39 & 78.0 \\
\hline Min. - Max. & \multicolumn{2}{|c|}{$0.10-0.32$} \\
\hline Mean \pm SD & \multicolumn{2}{|c|}{$0.13 \pm 0.06$} \\
\hline Median (IQR) & \multicolumn{2}{|c|}{$0.10(0.10-0.10)$} \\
\hline Intraocular pressure & \multirow{4}{*}{\multicolumn{2}{|c|}{$\begin{array}{c}11.0-17.0 \\
14.34 \pm 1.73 \\
14.0(13.0-16.0)\end{array}$}} \\
\hline Min. - Max & & \\
\hline Mean \pm SD. & & \\
\hline Median (IQR) & & \\
\hline
\end{tabular}

The central macular thickness post LASIK with $\mathrm{P}$ value 0.353 and has no statistically significant, alsot he retinal

nerve fiber layer thickness post LASIK with $\mathrm{P}$ value 0.090 and has no statistically significant (Table 2).

Table (2): Comparison between before and after according to macular thickness and retinal nerve fiber layer thickness

\begin{tabular}{|c|c|c|c|}
\hline & Before $(n=50)$ & After $(n=50)$ & $\mathbf{P}$ \\
\hline Macular thickness: & & & \multirow{6}{*}{0.353} \\
\hline Min. - Max. & $166.0-219.0$ & $164.0-217.0$ & \\
\hline Mean \pm SD & $188.9 \pm 13.66$ & $188.7 \pm 13.31$ & \\
\hline Median (IQR) & $187.0(178.0-201.0)$ & $187.5(177.0-201.0)$ & \\
\hline Change & \multicolumn{2}{|c|}{$\downarrow 0.22 \pm 1.66$} & \\
\hline$\%$ Change & \multicolumn{2}{|c|}{$\downarrow 0.10 \pm 0.87$} & \\
\hline $\begin{array}{l}\text { Retinal nerve fiber layer thickness: } \\
\text { Min. - Max. }\end{array}$ & $33.0-52.0$ & $32.0-52.0$ & \multirow{5}{*}{0.090} \\
\hline Mean \pm SD. & $40.18 \pm 5.31$ & $39.90 \pm 5.33$ & \\
\hline Median (IQR) & $39.0(36.0-44.0)$ & $38.50(36.0-43.0)$ & \\
\hline Change & \multicolumn{2}{|c|}{$\downarrow 0.28 \pm 1.14$} & \\
\hline$\%$ Change & \multicolumn{2}{|c|}{$\downarrow 0.67 \pm 2.94$} & \\
\hline
\end{tabular}




\section{DISCUSSION}

In this study age of patients ranged from 18 - 40 years old with mean 5.72 and standard deviation 28.64, under corrected visual acuity of patients ranged from $6 / 60$ to $6 / 12$ with mean 0.14 and standard deviation 0.64. IOP measurement of patients ranged from 11-17 with mean 1.73 and standard deviation 14.34. Best corrected visual acuity ranged from $6 / 12$ to $6 / 6$ with mean 0.06 and standard deviation 0.13. The central macula thickness preoperative ranged $166-219$ with mean 13.66 and standard deviation 188.9 while one month post-operative ranged $164-217$ with mean 13.31 and standard deviation 188.7 and there was no significant difference between them. The retinal nerve fiber layer thickness preoperative ranged from $33-52$ with mean 5.31 and standard deviation 40.18, while one month postoperative ranged 32 - 52 with mean 5.33 and standard deviation 39.90 and there is no significant difference between them.

In the current study, SD-OCT was used to evaluate the effect of applied suction during LASIK procedures on RNFL thickness in 50 myopic eyes, whether the flap was created by microkeratome. LASIK-induced corneal alterations do not affect OCT imaging, making the latter (OCT imaging) reliable in RNFL thickness evaluation in treated eyes.

Zhang et al. (2014) performed prospective clinical study of patients treated for myopia or myopic astigmatism using RTVue-100 OCT system to study the effect of suction on the macular thickness, ganglion cell complex, and the peripapillary RNFL during LASIK with microkeratome., In this study, the average foveal and parafoveal retinal thicknesses statistically increased $30 \mathrm{~min}$ after the surgery, while the perifoveal retinal thickness was not changed significantly. The foveal, parafoveal and perifoveal retinal thicknesses were not changed significantly 1 day, 3days; 1 week; 1 month, 3 months and 1year after surgery.

Zhang et al. (2014) stated that the RNFL thickness 30 min after surgery was less than before surgery in both groups, and changes were less in the femtosecond laser group than in the microkeratome group. But this might not be of significance and is unlikely to have clinical consequences, because the corneal edema may affect the image quality of examination results 30min after surgery. Moreover, the RNFL thickness had recovered to the preoperative level only 1 day after surgery.

Shrivastava et al. (2011) stated that is no significant difference between baseline, one month and six months postoperatively for mean RNFL and quadrants RNFL thickness.

Vidal-Sanz et al. (2012) performed this clinical study to compare the effect of suction on the macular thickness, ganglion cell complex, and the peripapillary RNFL during femtosecond laser-assisted LASIK and LASIK with microkeratome and there is no clinical significant between two groups.

\section{CONCLUSION}

There was no statistically significant correlation between the effect of suction by microkeratome during LASIK surgery and its efficacy on macular and retinal nerve fiber layer and LASIK was a safe procedure on posterior segment of the eye. 


\section{REFERENCES}

1. Bagetta $G$ and Nucci C. (2015): New Trends in Basic and Clinical Research of Glaucoma: A Neurodegenerative Disease of the Visual System - Part B, Volume 221. 1st Edition, Elsevier. Pp.412.

2. Corcoran KJ (2015): Macroeconomic landscape of refractive surgery in the United States. CurrOpinOphthalmol., 26(4):249-54.

3. Eldaly ZH, Abdelsalam MA, Hussein MS and Nassr MA. (2019): Comparison of Laser In Situ Keratomileusis Flap Morphology and Predictability by Wave Light FS200 Femtosecond Laser and Moria Microkeratome: An Anterior Segment Optical Coherence Tomography Study. Korean J Ophthalmol., 33(2): 113-121.

4. Gabriele ML, Wollstein G and Ishikawa H. (2011): Optical Coherent Tomography. history, current status and laboratory work. Invest Ophthalmol Vis Sci. , 4: 256-264.

5. Shrivastava A, Madu A and Schultz J. (2011): Refractive surgery and the glaucoma patient. CurrOpinOphthalmol., 22(4):215221.
6. Solomon KD, Fernández de Castro LE, Sandoval HP, Biber JM, Groat B and Neff KD. (2011): LASIK world literature review: quality of life and patient satisfaction. Ophthalmology, 116:691-701.

7. Vidal-Sanz M, Alarcón-Martínez L, Nadal-Nicolás FM, Alarcón-Martínez F, Valiente-Soriano FJ, de Imperial JM, Avilés-Trigueros M, Agudo-Barriuso $M$ and Villegas-Pérez MP. (2012): Understanding glaucomatous damage: anatomical and functional data from ocular hypertensive rodent retinas. Prog Retin Eye Res., 31(1):1-27.

8. Zhang $Y$, Shen $Q$ and Jia Y. (2016): Clinical Outcomes of SMILE and FS-LASIK Used to Treat Myopia: A Meta-analysis. J Reflect Surgery, 4: 256-264.

9. Zivkovic M, JaksicV, GiarmoukakisA, Grentzelos M, Zlatanovic M, Zlatanovic G, Miljkovic A, Jovanovic S, Stamenkovic M and Kymionis G. (2017): The Effect of LASIK Procedure on Peripapillary Retinal Nerve Fiber Layer and Macular Ganglion Cell-Inner Plexiform Layer Thickness in Myopic Eyes. Biomed Res Int., 2017:8923819. 


\section{تأثير الثفط باستخدام مشرط موريا على سمك الماقولة وطبقة

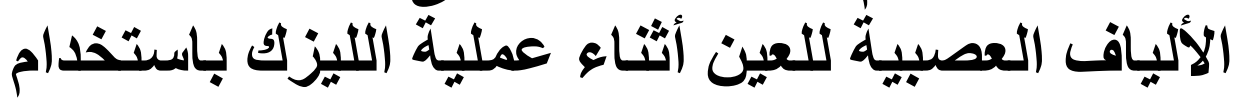 جهاز الماسح المقطعى لشبكية العين الثين}

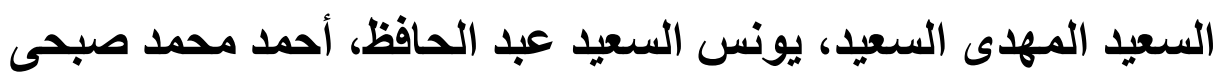
قسم طب وجراحة العيون، كلية الطب، جامعة الأزهر

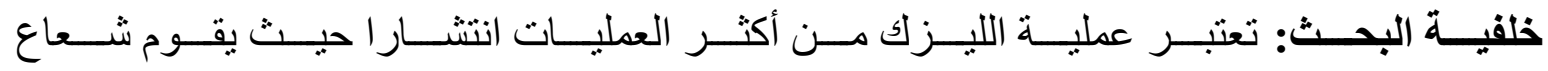

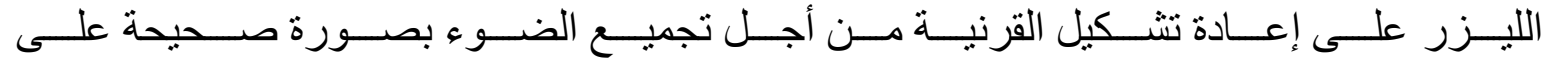

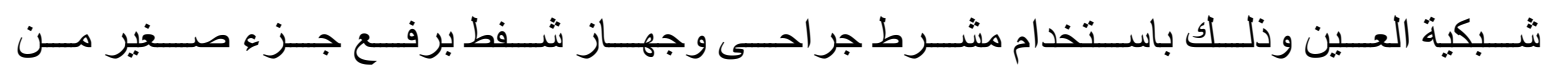
قرنية العين وتستغرق العملية حو الى 15 دقيقة.

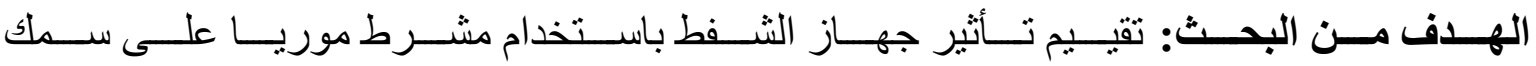

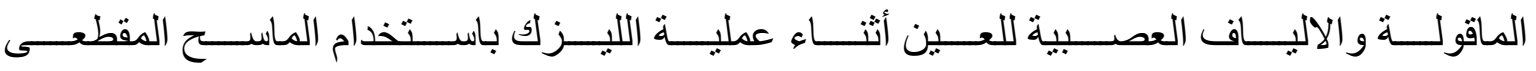
لثبكية العين.

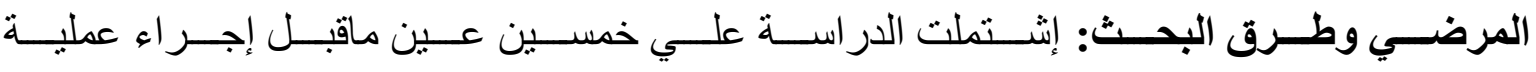

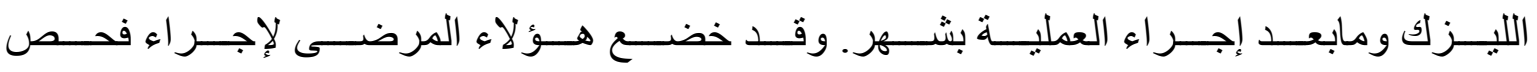

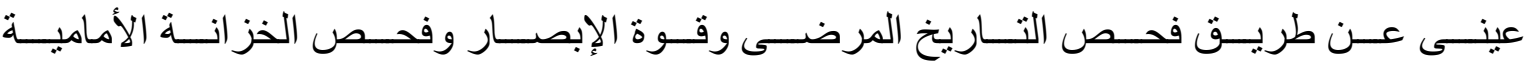

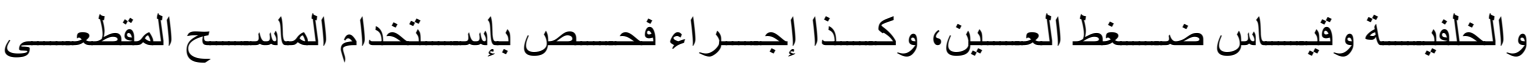
لثبكية العين لقياس سمك الماقولة و الالياف العصبية قبل وبعد العملية.

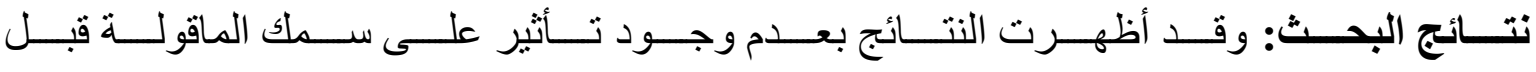

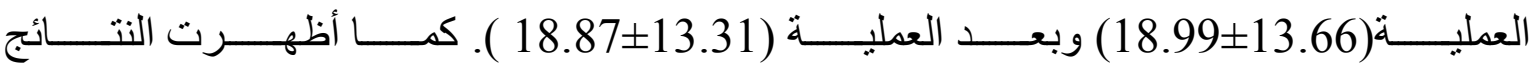

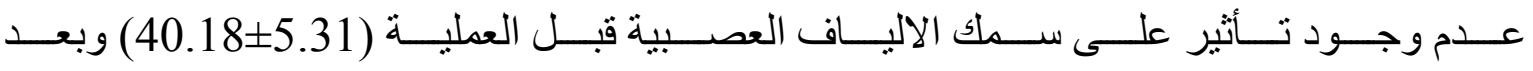

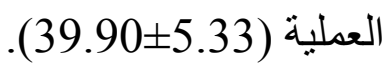

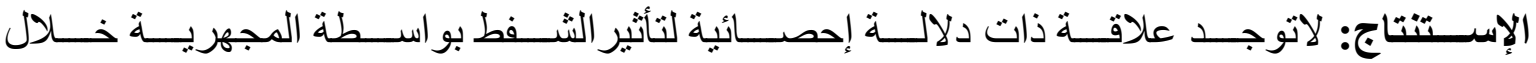

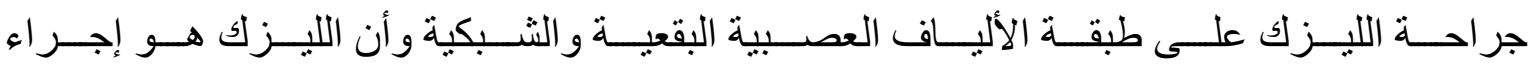
آمن على الجزء الخلفي من العين. 